\title{
RANCANG-BANGUN PROTOTYPE SISTEM KONTROL PINTU BERBASIS MIKROKONTROLER AT89S51 MENGGUNAKAN KARTU BER-PASSWORD DAN SENSOR FOTODIODA
}

\author{
Wildian dan Riki Saputra \\ Jurusan Fisika Universitas Andalas \\ wildian_unand@yahoo.com
}

\begin{abstract}
ABSTRAK
Telah dilakukan rancang-bangun prototype sistem buka-tutup pintu berbasis mikrokontroler AT89S51 menggunakan kartu ber-password dan sensor fotodioda. Kartu ber-password ini dibuat dari kartu ATM bekas yang diberi lubang dengan jumlah, posisi, dan jarak tertentu. Dengan menggunakan sistem sensor yang terdiri dari 8 pasang LED-fotodioda (jarak deteksi antara 4,7 cm hingga 5,2 cm), maka kartu ber-password yang disisipkan di antara LED dan fotodioda itu memiliki kode password 8-bit sesuai posisi dan jumlah lubang. Bagian kartu yang berlubang akan menyebabkan keluaran fotodioda low (antara $0 \mathrm{~V}$ hingga 1,5 V)., sedangkan bagian yang tak berlubang akan menyebabkan keluaran fotodioda high (antara $4 \mathrm{~V}$ hingga 4,5 V). Data digital 8-bit ini kemudian dibandingkan oleh mikrokontroler dengan data acuan yang telah disimpan di memorinya. Jika sesuai, maka mikrokontroler akan mengirimkan sinyal untuk membuka pintu, dan jika tidak sesuai, pintu akan tertutup.
\end{abstract}

Kata-kunci: kartu ber-password, LED, fotodioda, AT89S51.

\section{PENDAHULUAN}

Setiap orang pada dasarnya menginginkan rasa aman-yaitu rasa terlindungi dari bahaya dan hal-hal yang tak diinginkan lainnya. Rumah, kamar, lemari, brankas, atau ruang tertutup lainnya merupakan tempat yang lazim digunakan untuk berlindung atau tempat menyimpan benda-benda berharga. Ruang tertutup seperti itu selalu mempunyai bagian yang disebut pintu.

Pintu merupakan bagian dari suatu ruang tertutup yang dapat dibuka atau ditutup. Oleh karena itu, pintu biasanya dilengkapi dengan sistem pengaman tertentu. Sistem pengaman paling sederhana adalah sistem kunci mekanik dan palang pintu (grendel). Dewasa ini ada beragam sistem pengaman yang dapat diterapkan untuk membuka-tutup pintu, seperti sistem kunci mekanik dengan kombinasi angka, sistem kunci elektronik dengan kombinasi angka yang dimasukkan melalui keypad (Aini, 2006), atau sistem pengaman yang menggunakan sensor sidik jari, dan lain sebagainya.

Dalam makalah ini akan disampaikan hasil penelitian tentang rancang-bangun sistem buka-tutup pintu berdasarkan kode biner 8-bit yang dikodekan pada kartu ber-password.

\section{BAHAN DAN METODE}

Penelitian ini menggunakan metode rancang-bangun, meliputi perancangan perangkatkeras (hardware), perangkat-lunak (software), dan pengujian sistem secara keseluruhan. Sistem perangkat-keras dirancang secara blok per blok, mulai dari rangkaian catudaya, rangkaian sensor dan kartu ber-password, rangkaian mikrokontroler, hingga rangkaian penggerak motor dc. Diagram blok sistem kontrol ini ditunjukkan pada Gambar 1. 


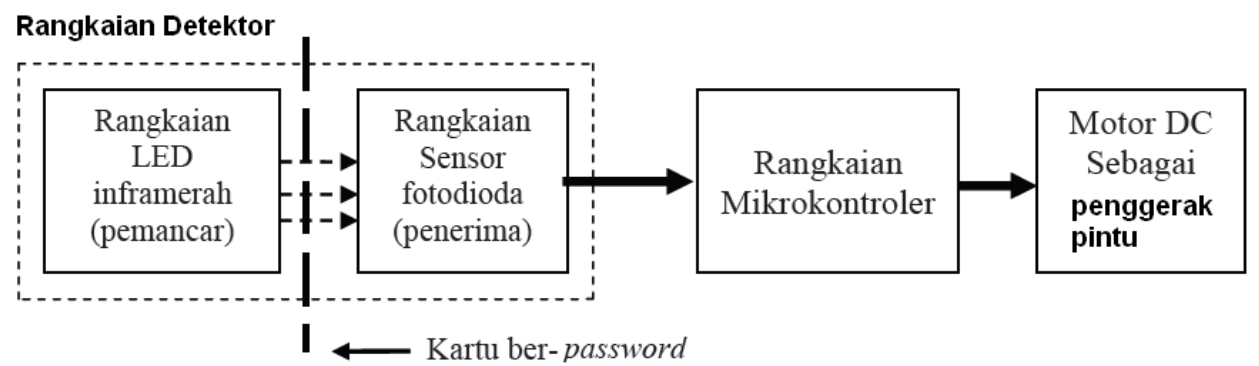

Gambar 1: Diagram blok sistem kontrol buka-tutup pintu dengan kartu ber-password.

Pintu akan terbuka atau tertutup bergantung pada kode biner 8-bit yang terbaca oleh kedelapan fotodioda. Kode biner untuk membuka pintu itu sendiri dikodekan pada kartu ber-password. Jika kode yang diterima oleh kedelapan fotodioda (yang kemudian diteruskan ke mikrokontroler) itu sesuai dengan kode yang tersimpan di memori, maka pintu akan terbuka. Jika tidak, maka pintu akan tertutup.

\section{Rancang-bangun Catudaya}

Sistim kontrol ini menggunakan catudaya $5 \mathrm{~V}$ (skematik rangkaiannya ditunjukkan pada Gambar 2). Rangkaian ini terdiri dari trafo step-down yang mengubah tegangan ac $220 \mathrm{~V}$ menjadi tegangan ac $9 \mathrm{~V}$. Tegangan ac tersebut kemudian diubah menjadi tegangan dc 9 $\mathrm{V}$ oleh rangkaian penyearah jembatan yang terdiri dari 4 buah dioda 1N4007 (atau bisa juga 1N4004) dan ditapis dengan kapasitor $\mathrm{C} 1=470 \mu \mathrm{F} / 25 \mathrm{~V}$. Sinyal ini kemudian diregulasi oleh IC regulator 7805 menjadi tegangan dc $5 \mathrm{~V}$. Sinyal tegangan dc ini kemudian ditapis lagi dengan kapasitor $\mathrm{C} 2=2200 \mu \mathrm{F} / 25 \mathrm{~V}$, dan arusnya dikuatkan oleh transistor T1 (2N3055).

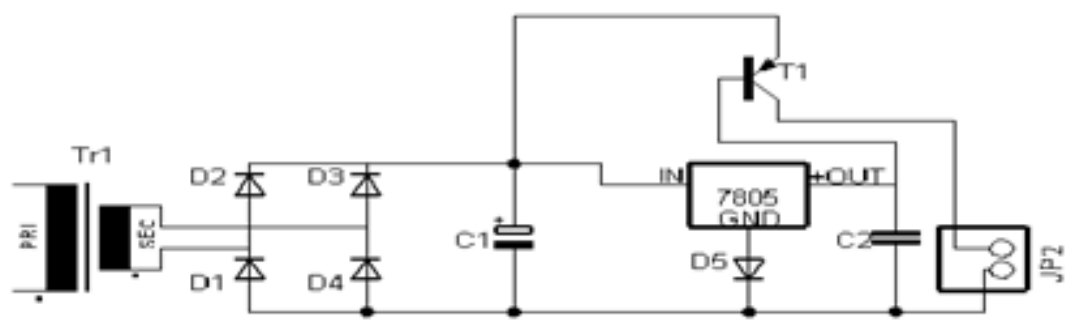

Gambar 2: Skematik rangkaian catu daya 5 volt.

\section{Rancang-bangun Sistem Sensor dan Kartu Ber-password}

Sistem sensor yang digunakan terdiri dari delapan LED inframerah dan delapan fotodioda, serta sejumlah resistor sebagai pembatas arus (Gambar 3).

LED (light emitting diode) yang berfungsi sebagai pemancar cahaya inframerah dipasang berhadapan dengan fotodioda (sebagai penerima). Untuk membatasi kuat arus yang mengalir melalui LED, maka masing-masing LED dihubungkan secara seri dengan resistor $100 \Omega$, sedangkan untuk fotodioda digunakan resistor $1 \mathrm{k} \Omega$.

Kartu ber-password pada sistem kontrol ini dapat dibuat dari kartu ATM bekas (atau semacam itu) yang diberi lubang dengan jumlah, jarak, dan posisi tertentu (Gambar 4). Posisi, jarak, dan jumlah lubang inilah yang dijadikan sebagai kode password untuk membuka pintu.

Lubang pada kartu ber-password akan menyebabkan fotodioda dapat menerima cahaya dari LED pasangannya. Sebaliknya, bagian kartu yang tidak berlubang akan menyebabkan fotodioda tidak dapat menerima cahaya dari LED. Jumlah dan posisi lubang pada kartu tersebut akan menentukan fotodioda mana saja yang akan menerima 
cahaya dari LED-nya masing-masing. Data digital 8-bit ini kemudian digunakan sebagai data masukan bagi mikrokontroler untuk menentukan apakah pintu dibuka atau ditutup.

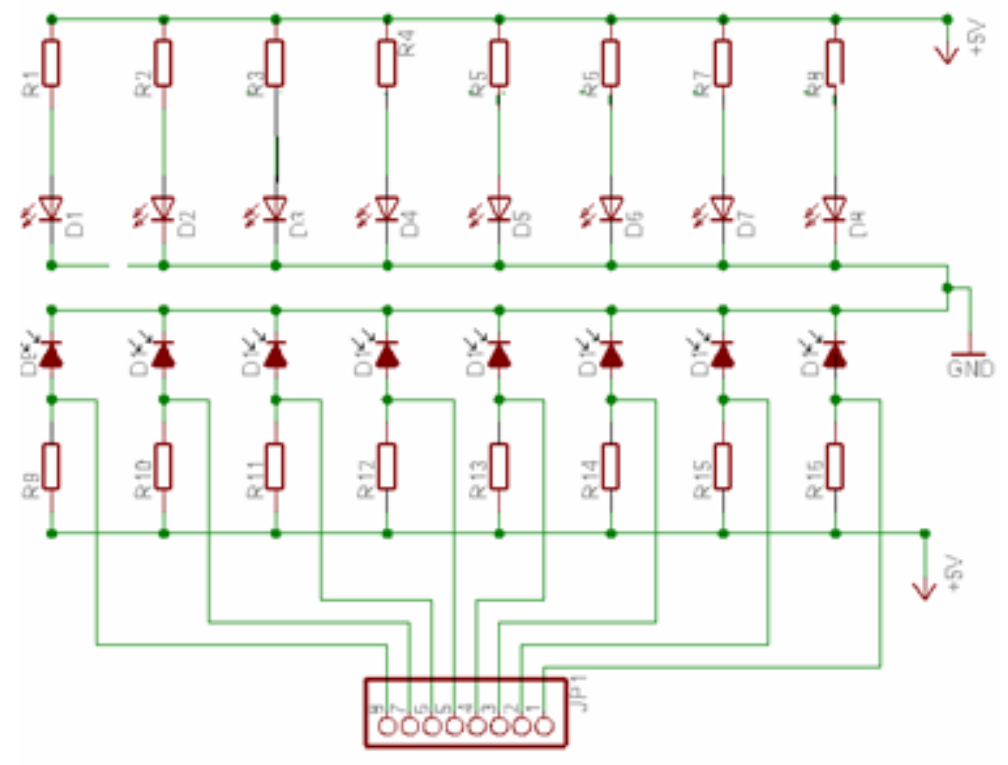

Ke Port PO

Gambar 3: Skematik rangkaian sistem sensor kartu ber-password.

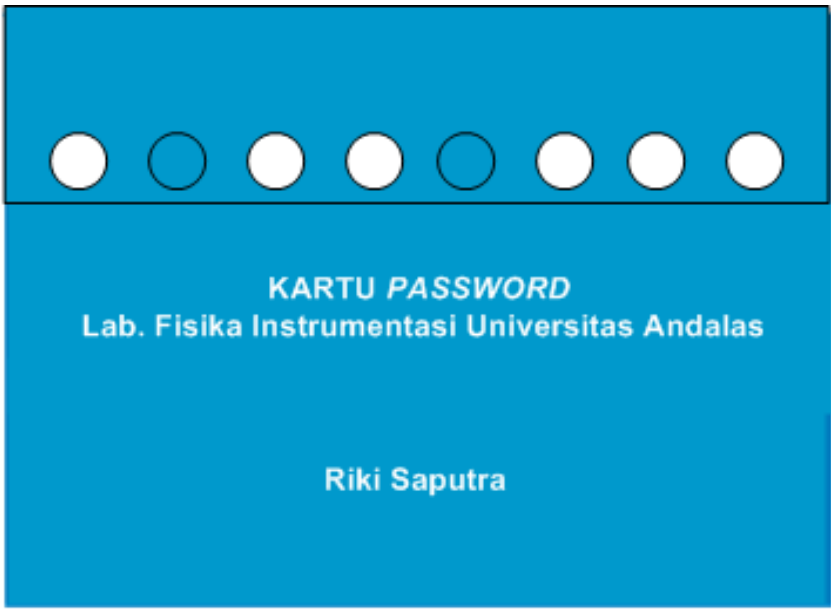

Gambar 4: Kartu berlubang-enam dengan kode password B7H.

\section{Rancang-bangun Sistem Minimum Mikrokontroler}

IC AT89S51 merupakan mikrokontroler dengan sejumlah fitur penting: CPU 8-bit, osilator internal dan rangkaian pewaktu (timer), RAM Internal 128 byte, In System Programmable Flash Memory 4K byte, dan 4 buah programable port I/O. Dalam aplikasinya, mikrokontroler ini harus dilengkapi beberapa rangkaian tambahan seperti rangkaian osilator (menggunakan kristal $12 \mathrm{MHz}$ ) dan rangkaian reset, seperti ditunjukkan pada Gambar 5. 


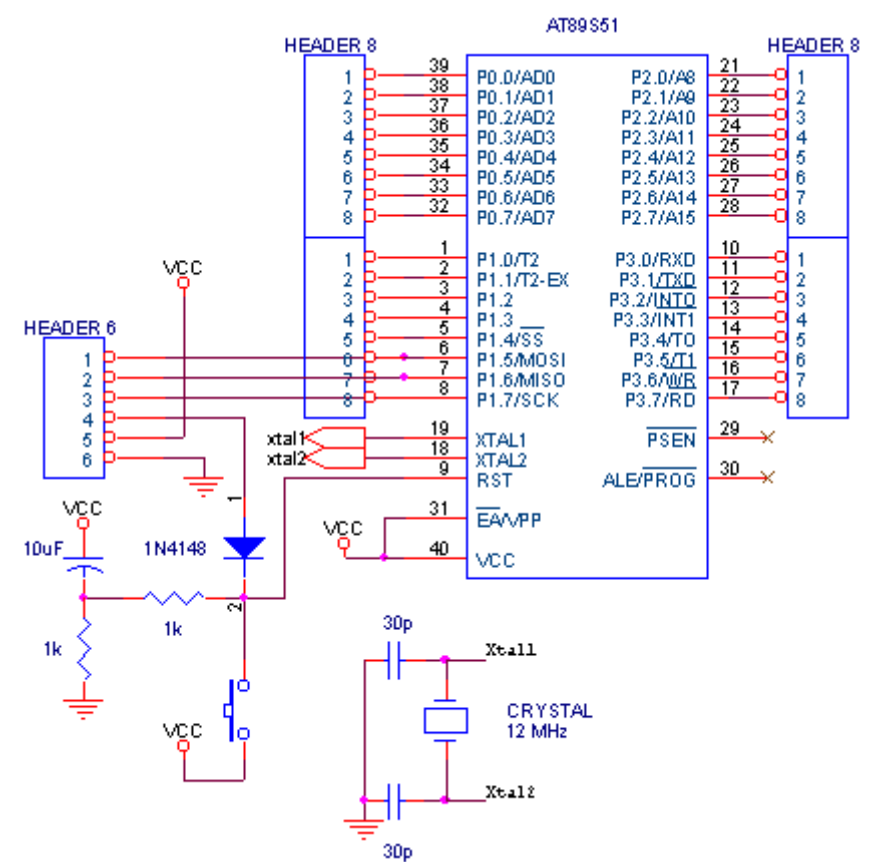

Gambar 5: Skematik sistem minimum rangkaian pengontrol.

\section{Rancang-bangun Sistem Penggerak Motor DC}

Untuk membuka dan menutup pintu digunakan dua buah motor de - suatu motor listrik arus searah yang akan berputar selama mendapat catudaya. Arah putaran motor ini akan berubah jika polaritas catudayanya dibalik. Motor dc $5 \mathrm{~V}$ ini digerakkan oleh arus dari rangkaian penggerak (driver) berupa transistor yang dihubungkan ke relay (Gambar 6).

Relay berfungsi sebagai saklar elektromagnetis yang bekerja ketika kumparan di dalam relay tersebut dialiri arus, sedangkan rangkaian penggerak motor dc akan bekerja ketika mendapat sinyal high dari mikrokontroler AsT89S51 melalui port P1. Sinyal high untuk menggerakkan motor dc_1 (untuk membuka pintu) disalurkan melalui port P1.3, sedangkan untuk motor dc_2 (untuk menutup pintu) disalurkan melalui port P1.4.

\section{Perancangan Perangkat-lunak}

Sistem kontrol ini dijalankan berdasarkan instruksi-instruksi yang ditanamkan di mikrokontroler. Instruksi-instruksi tersebut disusun secara sistematis dan logis dalam bahasa assembly dengan menggunakan perangkat-lunak Reads51. Perancangan diagram alir (flowchart) programnya ditunjukkan pada Gambar 7. 


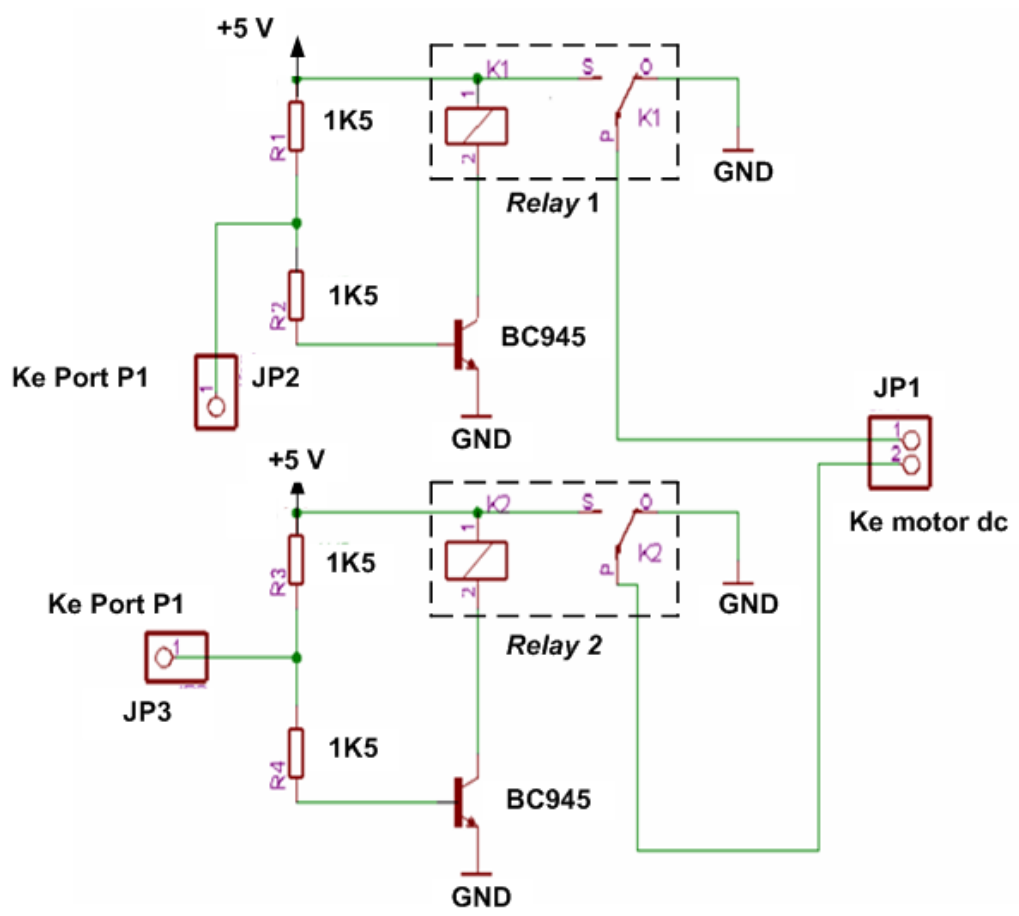

Gambar 6: Rangkaian penggerak motor dc.

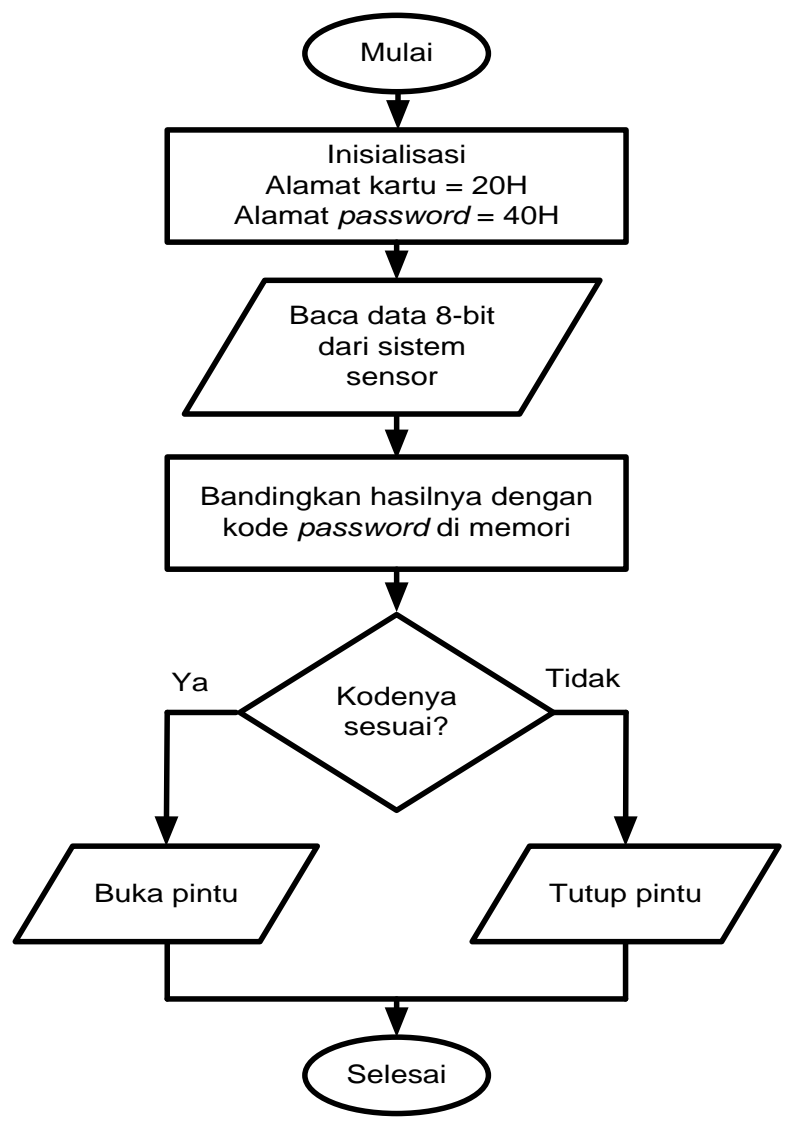

Gambar 7: Diagram alir sistem kontrol buka-tutup pintu dengan kartu password. 


\section{HASIL DAN DISKUSI}

Dari penelitian ini telah dihasilkan sebuah prototype sistem kontrol pintu berbasis mikrokontroler AT89S51 yang bekerja berdasarkan kartu ber-password yang dideteksi dengan sensor fotodioda, seperti ditunjukkan pada Gambar 8.

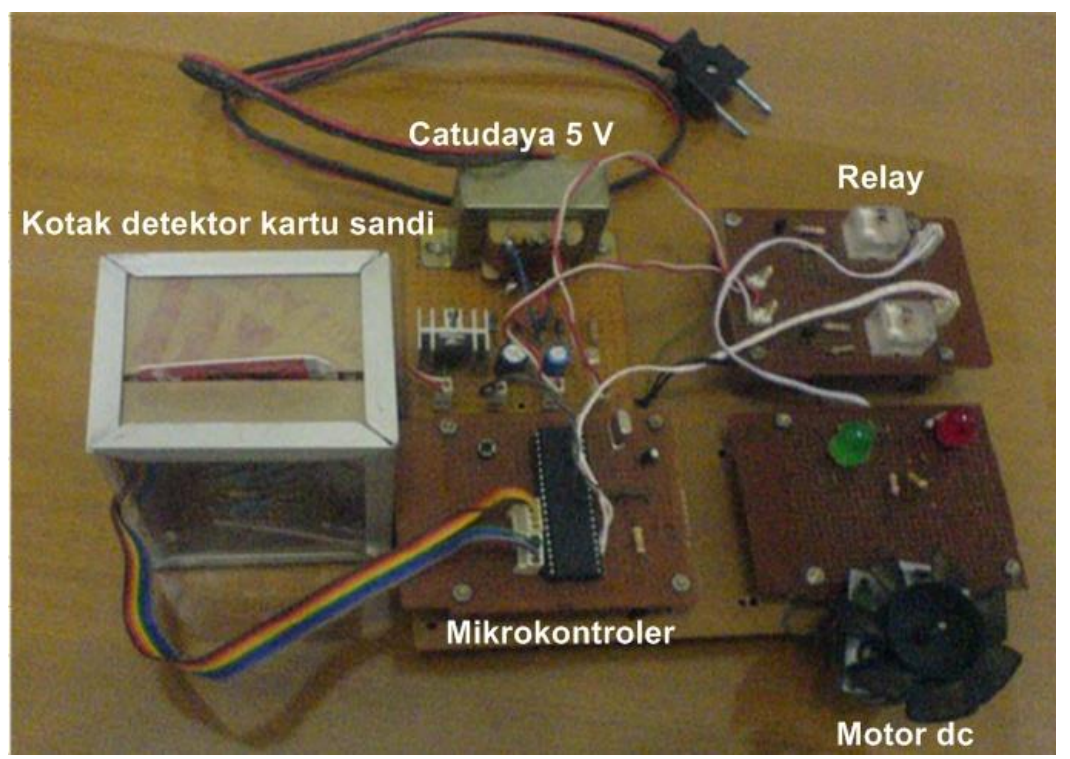

Gambar 8: Bentuk fisik sistem kontrol motor de dengan kartu ber-password.

Berdasarkan hasil pengujian, alat ini telah terbukti dapat bekerja sesuai dengan yang diharapkan; artinya motor dc akan berputar untuk menutup pintu jika kode kartu berpassword yang digunakan sesuai dengan data kode password yang ada di mikrokontroler. Kode pada kartu dapat diubah dengan cara mengubah jumlah dan/atau posisi lubang, serta mengubah kode password yang ditanamkan pada mikrokontroler. Berdasarkan hasil pengukuran diperoleh bahwa tegangan keluaran sensor fotodioda berkisar antara $4 \mathrm{~V}$ hingga 4,5 V ketika cahaya inframerah dari LED terhalang kartu, dan ketika cahaya tersebut tidak terhalang kartu, tegangan keluarannya antara $0 \mathrm{~V}$ hingga $1,5 \mathrm{~V}$. Jarak antara LED inframerah (pemancar) dengan sensor fotodioda (penerima) adalah antara $4,7 \mathrm{~cm}$ hingga $5,2 \mathrm{~cm}$, dan ketebalan kartu yang digunakan (kartu ATM, SIM Card pulsa) adalah antara $1 \mathrm{~mm}$ hingga $2 \mathrm{~mm}$.

\section{KESIMPULAN}

Berdasarkan pengujian dan analisis data hasil pengukuran yang telah dilakukan maka dapat diambil kesimpulan sebagai berikut:

1. Prototype sistem kontrol pintu berbasis mikrokontroler AT89S51 yang bekerja berdasarkan kartu ber-password yang dideteksi dengan sensor fotodioda ini dapat bekerja sesuai dengan yang diharapkan.

2. Tegangan keluaran sensor fotodioda akan berlogika high (antara $4 \mathrm{~V}$ hingga 4,5 V) ketika cahaya inframerah dari LED terhalang kartu, dan ketika cahaya tersebut tidak terhalang kartu, tegangan keluarannya berlogika low (antara $0 \mathrm{~V}$ hingga $1,5 \mathrm{~V})$.

3. Jarak antara LED inframerah (pemancar) dengan sensor fotodioda (penerima) adalah antara $4,7 \mathrm{~cm}$ hingga $5,2 \mathrm{~cm}$.

4. Ketebalan kartu yang digunakan (kartu ATM, SIM Card pulsa) adalah antara 1 mm hingga $2 \mathrm{~mm}$. 


\section{SARAN}

Prototype sistem kontrol ini perlu dikembang lebih lanjut dengan menggunakan sistem penggerak motor dc yang dapat menggerakkan beban yang lebih besar.

\section{DAFTAR KEPUSTAKAAN}

1. Ayala, K. J., 1991, The Microconroller 8051: Architecture, Programming, and Application, West Publishing Company, St. Paul, MN.

2. Buchla, D., McLachlan, W., 1992, Applied Electronic Instrumentation And Measurement, Prentice-Hall, Inc., Englewood Cilffs, New Jersey.

3. Fraden, J., 1996, Handbook Of Modern Sensors Physics second edition, Themoscan Inc., San Diego, California

4. Hewes, J., 2010, Relay, The Electronics Club, http://www.kpsec.freeuk.com/

5. Malvino, A.P., 1993, Electronic Principles, $5^{\text {th }}$ Ed., Macmillan/McGraw-Hill, Singapore. 